\title{
Hormonal correlates of 'masculinization' in female spotted hyaenas (Crocuta crocuta). 1. Infancy to sexual maturity
}

\author{
S. E. Glickman ${ }^{1}$, L. G. Frank ${ }^{1}$, S. Pavgi ${ }^{2}$ and P. Licht ${ }^{2}$ \\ Departments of ${ }^{1}$ Psychology and ${ }^{2}$ Integrative Biology, University of California, Berkeley, \\ $C A 94720, U S A$
}

\begin{abstract}
Summary. This report is concerned with hormone concentrations accompanying sexual maturation in a highly 'masculinized' female mammal, the spotted hyaena, Crocuta crocuta. Plasma concentrations of testosterone, androstenedione and oestrogen were determined by radioimmunoassay in a longitudinal study of 12 female and eight male hyaenas $2 \cdot 5-62 \cdot 5$ months old. Concentrations of testosterone were significantly higher in males than in females after 26.5 months of age, but earlier measurements did not differ between sexes. Mean testosterone concentrations in adult female hyaenas $(0.4$ $0.5 \mathrm{ng} \mathrm{ml}^{-1}$ ) were similar to those in several other female mammals that do not display a 'masculine' profile, but mean concentrations of androstenedione $\left(2 \cdot 5-5 \cdot 5 \mathrm{ng} \mathrm{ml}^{-1}\right)$ in female hyaenas were significantly higher than in males $\left(1 \cdot 0-2 \cdot 0 \mathrm{ng} \mathrm{ml}^{-1}\right)$, at most ages. Oestrogen could not be detected $\left(<0.03 \mathrm{ng} \mathrm{ml}^{-1}\right)$ in females until about 14 months of age and then increased (to approximately $0.13 \mathrm{ng} \mathrm{ml}^{-1}$ ) between 18 and 30 months; oestrogen remained undetectable in males. This rise in oestrogen in females corresponded to nipple enlargement and to changes in the size and elasticity of the urogenital meatus, permitting copulation and parturition through the clitoris. Gonadectomy (two males and four females) at 4-7 months resulted in nondetectable concentrations of testosterone and oestrogen and a marked attenuation in androstenedione (to approximately $0.39 \mathrm{ng} \mathrm{ml}^{-1}$ ), indicating that the gonads are the major source of these three steroids. Gonadectomy also eliminated sex differences in weight, nipple development and elasticity of the urogenital meatus.
\end{abstract}

Kevrords: steroids; masculinization; development; hyaena

\section{Introduction}

Adult female spotted hyaenas (Crocuta crocuta) are larger and more aggressive than males, and are dominant to males in a broad array of social situations (Kruuk, 1972; Frank, 1986b; Frank et al., 1989). The external genitals of female spotted hyaenas are remarkably similar to those of the male. The hypertrophied clitoris is traversed by a central urogenital canal through which the female hyaena urinates, receives the male during copulation and gives birth (Matthews, 1939; Neaves et al., 1980; Frank et al., 1990). The internal reproductive tracts follow the typical pattern of a female mammal (Matthews, 1939). Male and female hyaenas regularly exhibit similar erections during 'meeting ceremonies', in the course of which the subordinate animal generally initiates the ceremony by offering its erect phallus for olfactory inspection by the dominant member of the pair (Kruuk, 1972).

The preceding array of morphological and behavioural characteristics has led to a search for androgens in the circulation of female spotted hyaenas that might account for their 'masculine' morphology and behaviour. Equally important, in the light of their masculinized genitals, are the endocrine mechanisms permitting the female hyaena to engage in successful reproductive activities. 
Some authors (Racey \& Skinner, 1979; Lindeque et al., 1986) have concluded that there is no sex difference in plasma testosterone, while others (Frank et al., 1985a) have obtained significantly higher concentrations in males than in females. Plasma androstenedione is generally higher in females than in males, although the timing of significant differences has varied among studies (Racey \& Skinner, 1979; Lindeque et al., 1986; Glickman et al., 1987). All of the preceding work with subadult and adult hyaenas has been based on single samples from a diverse assortment of wild animals that were shot or chemically immobilized. Failure to find statistically significant differences could, in part, be explained by the enhanced variability inherent in this type of sampling.

The data presented in this report were gathered as part of a project devoted to the longitudinal study of behavioural and morphological sexual differentiation in spotted hyaenas maintained in captivity. Our research has concentrated on determining which hormones, secreted or metabolized by which structures, at what times of development, could account for the array of 'masculine' traits, while maintaining successful reproduction in female hyaenas.

Presumably, most organizational effects of such hormones occur during prenatal, or early postnatal periods (genitalia are already 'masculinized' at birth). However, concurrent studies of behaviour of our study animals indicated that ovariectomy drastically reduced female aggressiveness towards males (Baker, 1990). Given the typical activating effects of androgens on aggressive behaviour in male mammals (e.g. Bouissou, 1983), we were particularly interested in the possibility that ovariectomy produces a substantial decrease in plasma androgens in female spotted hyaenas, possibly accounting for the reduction in female aggressiveness towards males.

Mating in these animals involves female reception of the male through the clitoris. We were, therefore, also interested in the emergence of steroid-dependent changes in the urogenital meatus of the female, associated with the attainment of puberty, permitting the male to achieve entry. Histological evidence from wild hyaenas (Matthews, 1939) as well as behavioural observations from nature suggest that male hyaenas are reproductively mature at 2 years of age and females at 3 years of age (Frank, 1986a). In this paper, we (i) describe the time-course of sexual maturation, as reflected in increments in testosterone, androstenedione and oestrogen; (ii) re-examine sexual differentiation of androgen secretion in a stable population of known age; and (iii) assess ovarian contributions to steroid secretion and morphology through comparison between intact and gonadectomized animals at different ages. This analysis was restricted to nonpregnant female hyaenas. It is now clear that hormonal profiles are altered markedly during pregnancy (Licht et al., 1992).

\section{Methods}

\section{Animals}

Twenty spotted hyaenas ( 12 females and 8 males), collected as infants in the Narok District of south-west Kenya in 1984-85 were initially housed in two $40 \times 100 \mathrm{ft}$ indoor and outdoor enclosures as two cohorts comprising ten animals per group. Two females from each cohort and two males from the second cohort were gonadectomized at 4-7 months old. At 22-24 months old, unacceptable consequences of aggression in the original cohorts led us to subdivide the animals into smaller groups.

\section{Blood sampling}

Animals were immobilized (with blowdarts) with intramuscular injections of ketamine (4-6 $\left.\mathrm{mg} \mathrm{kg}^{-1}\right)$ and xylazine ( $1 \mathrm{mg} \mathrm{kg} \mathrm{k}^{-1}$ ). Blood was drawn from the jugular vein using a 22 -gauge needle-vacutainer system. The blood was then centrifuged at $1000 \mathrm{~g}$ for $5 \mathrm{~min}$ and the plasma drawn and frozen for subsequent radioimmunoassay.

During the first year of study with the first cohort, we sampled hormones on a monthly basis. However, concern with the possible effects of frequent immobilization and sampling on concurrent or long-term behavioural assays led us to restrict sampling to intervals of 2-4 months during subsequent phases of this research.

\section{Morphological measurements}

During blood sampling, animals were weighed and measures taken of phallic and nipple development. Nipple diameter was measured with callipers. Initially, the length of the urogenital meatus was measured with the aid of 
forceps inserted into the opening and exerting a constant tension. Subsequently, to assess developmental changes in the length and elasticity of the urogenital meatus as a function of age, sex and gonadal status, we developed an instrument with one fixed and one movable probe that could be inserted into the meatus. A tension of $50 \mathrm{or} 100 \mathrm{~g}$ could then be placed on the probe and the diameter of the opening measured with callipers.

\section{Measurements of plasma steroids}

Plasma samples were extracted with diethyl ether (Mallinkrodt; Boston, MA) for radioimmunoassay of steroids, by procedures detailed previously, using ${ }^{3} \mathrm{H}$-labelled steroids (New England Nuclear; Boston, MA) and charcoal to separate free from bound hormone (Licht et al., 1982). Recovery of steroids typically exceeded $85-90 \%$ based on separate tests with labelled internal or cold standards, and no further adjustments for recovery were made in calculations.

Testosterone was measured with an antiserum that was cospecific for testosterone and $5 \alpha$-dihydrotestosterone using testosterone $\left[1,2,6,7_{-}^{3} \mathrm{H}(\mathrm{N})\right]$. Androstenedione was measured with a specific antiserum with androstenedione $\left[1,2,6,7-{ }^{3} \mathrm{H}(\mathrm{N})\right]$ as label. Oestrogen was measured with an antiserum that was cospecific for oestradiol and oestrone with oestradiol $\left[2,4,6,7 \cdot{ }^{3} \mathrm{H}(\mathrm{N})\right]$ as tracer; and progesterone was measured with a specific antiserum using Pro[1,2,6.7- $\left.{ }^{3} \mathrm{H}(\mathrm{N})\right]$ as label. Labelled steroids were obtained from New England Nuclear.

For routine analyses, extracts were reconstituted in phosphate-buffered saline containing gelatin, divided into aliquots (corresponding to $10-300 \mu \mathrm{l}$ plasma) and assayed separately with each of the four major antisera. The minimal levels of detection for the four steroids in routine assays of nonchromatographed samples, based on the maximum sample sizes tested, were $0.075 \mathrm{ng}$ testosterone $\mathrm{ml}^{-1}, 0.05 \mathrm{ng}$ androstenedione $\mathrm{ml}^{-1}, 0.03 \mathrm{ng}$ oestrogen $\mathrm{ml}^{-1}$ and $0 \cdot 10 \mathrm{ng}$ progesterone $\mathrm{ml}^{-1}$. For statistical analysis, nondetectable values were conservatively assumed to be equivalent to these minimal detectable values. Interassay and intra-assay coefficients of variation were $<12$ and $<10 \%$, respectively, for all assays.

A limited series of plasma samples from each sex were analysed by celite chromatography (Wingfield \& Farner, 1975). All progesterone and androstenedione immunoreactivity co-chromatographed with labelled progesterone and androstenedione, respectively. However, only $60-80 \%$ of the total testosterone immunoreactivity chromatographed as testosterone; the remainder was recovered in the dihydrotestosterone fraction. Likewise, of the total oestradiol measured, less than half chromatographed with oestradiol; most of the remainder chromatographed as oestrone. However, the chromatographed values for testosterone and oestradiol were correlated significantly $(P<0.01)$ with nonchromatographed values for the two steroids. Because of the nonspecificity of these antisera and the presence of the other crossreacting steroids, we adopted the convention of referring to the nonchromatographed values as 'testosterone' and to oestradiol as 'oestrogen'.

\section{Averaging data within age periods}

The interval between 2.5 and 62.5 months was divided into nine age periods. Between one and four samples had been collected for each subject during each of these periods. Statistical analyses were carried out using averaged values for each animal during each age period. These values provided the most stable estimate of steroid concentration for each individual during particular periods of development. The initial age blocks were selected with respect to the timing of gonadectomies, which had been performed between 4 and 7 months of age. Thus, the pre-gonadectomy block (age period 1) included samples taken between 2.5 and 4.5 months of age, whereas age period 2 (after gonadectomy) comprised samples obtained between 6.5 and 8.5 months of age. The duration of age periods $3-9$ reflected the frequency of our sampling, i.e. as animals matured, we sampled less frequently. The interval between 8.5 and 38.5 months of age was divided into 6-month periods, with midpoints of 11.5 (period 3), 17.5 (period 4), 23.5 (period 5), 29.5 (period 6) and 35.5 (period 7) months. The final 2 years was divided into 12 -month periods, with midpoints of 44.5 (period 8 ) and 56.5 (period 9) months.

\section{Statistical analyses of averaged data}

All of the steroid data were analysed within age periods using two-factor analysis of variance (ANOVA), after log transformation of individual values to compensate for significant heterogeneity of variance between groups. There were two instances, involving two females, where all available samples for a particular age period were obtained when the animals were pregnant. To complete the ANOVA matrix we used average values, based on the periods immediately before and immediately after the missing cases. If an initial two-factor ANOVA, with repeated measures on the age dimension, revealed a significant effect of age, treatment condition (sex or gonadal status), or a significant interaction between age and treatment condition, further tests were carried out to localize the source of the effect(s). The signifcance of differences within treatment groups as a function of age was evaluated using ANOVA for repeated measures, followed by comparisons with Fisher's protected least significant difference (PLSD) statistic, which adjusts for the number of comparisons under study. Differences between treatment groups, within age periods, were evaluated by factorial ANOva followed by comparisons using Fisher's PLSD statistic. In several cases, where most samples from one of the groups was in the nondetectable range, significance between groups was assessed with a nonparametric statistic, the Mann-Whitney U test. 


\section{Results}

\section{Individual records}

Representative developmental trends in individual plasma concentrations of 'testosterone', androstenedione and 'oestrogen' are presented for two intact male and two intact female hyaenas (Fig. $1 \mathrm{a}-\mathrm{c}$ ). These records include all available samples, other than those taken during pregnancy. For all three steroids, there was great variability between successive samples. However, there were also consistent sex differences, reflected in the maximum values presented as animals matured. For example, in regard to 'testosterone' (Fig. 1c), there were no clear sex differences among the four hyaenas before about 21 months of age, but after that all the values greater than $1 \mathrm{ng} \mathrm{ml}^{-1}$ were from the two males. The reverse situation obtained for plasma concentrations of androstenedione (Fig. 1b); all plasma values of androstenedione greater than $6 \mathrm{ng} \mathrm{ml}^{-1}$ were presented by females. Moreover, there were no obvious age-related changes in this steroid. Plasma 'oestrogen' concentrations fluctuated near the level of detectability (approximately $20 \mathrm{pg} \mathrm{ml}^{-1}$ ) throughout maturation in both males, never exceeding $0.05 \mathrm{ng} \mathrm{ml}^{-1}$. Both females presented oestradiol concentrations higher than the maximum male values at 18-20 months of age and, after that commonly exhibited values between $0 \cdot 1$ and $0 \cdot 3 \mathrm{ng} \mathrm{ml}^{-1}$ (Fig. 1a).

Progesterone was not measured routinely in males because most measured values were $<1 \mathrm{ng}$ $\mathrm{ml}^{-1}$. Of 310 measurements for females with no evidence of sustained pregnancies, progesterone was $<1 \mathrm{ng} \mathrm{ml}^{-1}$ in 213 samples, $1-10 \mathrm{ng} \mathrm{ml}^{-1}$ (mean 2.7) in 79 samples and $>10 \mathrm{ng} \mathrm{ml}^{-1}$ (mean $76)$ in 18 cases. The intermediate values were first observed at 4 months of age and were scattered throughout the study. The few higher values $\left(>10 \mathrm{ng} \mathrm{ml}^{-1}\right)$ did not occur until after 28 months (seven occurred between 28 and 30 months).

\section{Statistical analyses of averaged data}

'Testosterone'. Increases in 'testosterone' concentrations with age were (Fig. 2c) significant for intact males $\left(F_{8,32}=4 \cdot 11, P<0.001\right)$, and marginally significant for intact females $\left(F_{8,40}=2 \cdot 05\right.$, $P<0 \cdot 10>0.05)$. Concentrations of testosterone in males during age periods $6,7,8$ and 9 were significantly greater than those during age periods $1,2,3$ and $4(P<0.05)$, with the exception of the comparison between age periods 1 and 8. 'Testosterone' concentration during age period 5 was significantly higher than in age period 2 and lower than in age period $9(P<0.05)$.

Intact males displayed significantly higher concentrations of testosterone $(P<0.05)$ than intact females during age periods 6,7 and 9, but not during any of the earlier age periods. In both sexes, gonadectomy resulted in a significant reduction in 'testosterone' values $(P<0.05)$ during all age periods after, but not before, surgery. At the time of maximum production of 'testosterone' by females (38.5-50.5 months old), ovariectomy resulted in average values of 'testosterone' that were only $6 \%$ of intact values. 'Testosterone' concentrations were at or below levels of detectability $\left(0.075 \mathrm{ng} \mathrm{ml}^{-1}\right)$ in most samples from all six gonadectomized animals.

The variability between successive samples from the same individual suggested another estimate of sex differences: maximum 'testosterone' values attained by each individual in the entire set of data (Table 1). These individual maximum values were averaged (Table 1): males and females differed significantly i.e. there was no overlap between males and females in maximum 'testosterone' concentrations (Mann-Whitney $U_{8,6}=0, P<0.001$ ). The highest concentration displayed by a nonpregnant female was $1.47 \mathrm{ng} \mathrm{ml}^{-1}$. The lowest maximum 'testosterone' value measured in any male was $1.79 \mathrm{ng} \mathrm{ml}^{-1}$.

Androstenedione. Effects of age on androstenedione concentrations (Fig. 2b) were significant for intact females $\left(F_{8,56}=2 \cdot 42, P<0.05\right)$, but not for intact males $\left(F_{8,40}=0.63 ; P>0 \cdot 10\right)$. Plasma androstenedione was lowest during age period 5 . At this time, androstenedione was significantly 

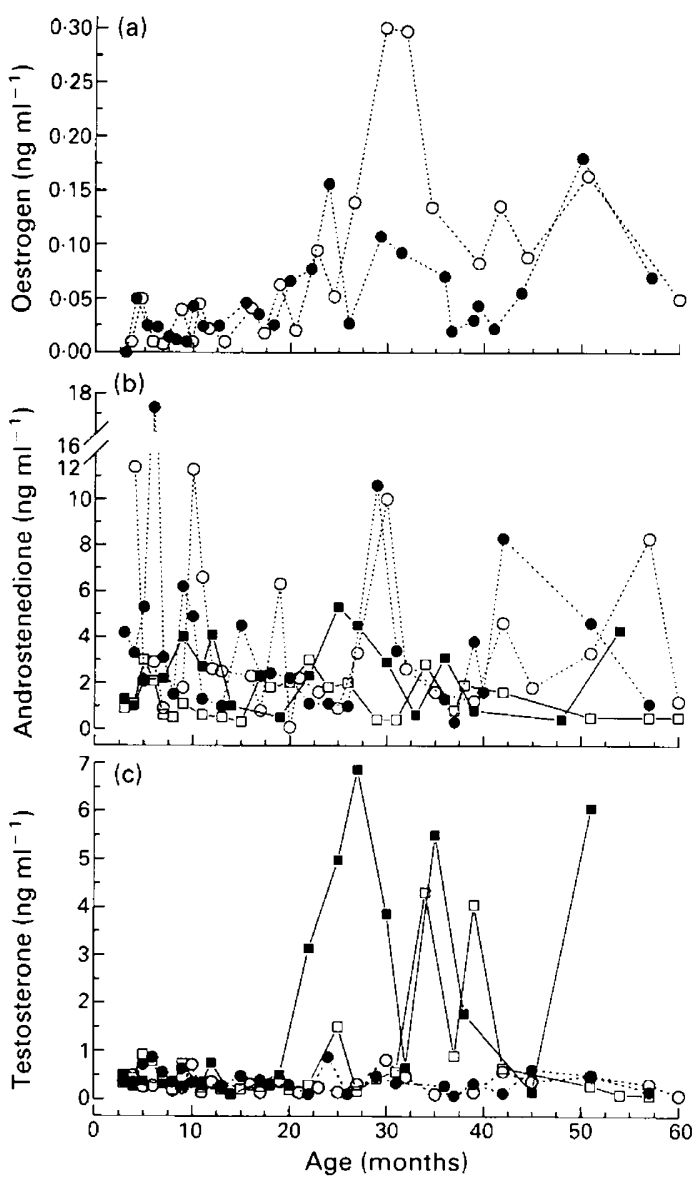

Fig. 1. Concentrations of (a) oestrogen (b) androstenedione and (c) testosterone + dihydrotestosterone in plasma in two female $(O, 0)$ and two male $(\square, \boldsymbol{\square})$ spotted hyaenas as a function of age. Points show individual values.

lower $(P<0.05)$ than during age periods 1, 3, 6 and 8. Age period 6 represented the highest concentration of plasma androstenedione, differing significantly from age periods 2,4 and 5 .

There were no significant differences between intact and gonadectomized animals $(P>0 \cdot 10)$ before surgery (age period 1). Removal of the gonads significantly reduced androstenedione concentrations during all postoperative periods for females $(P<0.05)$, but not for males, when intact subjects were compared with gonadectomized subjects. However, circulating androstenedione (averaging $0.39 \mathrm{ng} \mathrm{ml}^{-1}$ ) remained detectable in all post-gonadectomy samples.

Plasma concentrations of androstenedione in intact females were significantly higher than in intact males $(P<0.05)$ for age periods $1,3,4,6,7$ and 8 . Examination of maximum values of androstenedione for each subject during the entire study (Table 1) also revealed that all females developed significantly higher peak concentrations than all males (Mann-Whitney $\left.U_{8,6}=0, P<0.001\right)$. Plasma androstenedione was consistently higher than 'testosterone' in samples from females and in most samples from males. As expected from relative androstenedione and 'testosterone' values, the androstenedione: 'testosterone' ratio was much higher in females $(15 \cdot 7 \pm 1 \cdot 7, n=198)$ than in males $(4 \cdot 74 \pm 0.48, n=139)$. Individual plasma androstenedione and 'testosterone' were significantly and positively $(P<0.01)$ correlated in both sexes (females, $r=0.68$; males, $r=0.44$ ). 


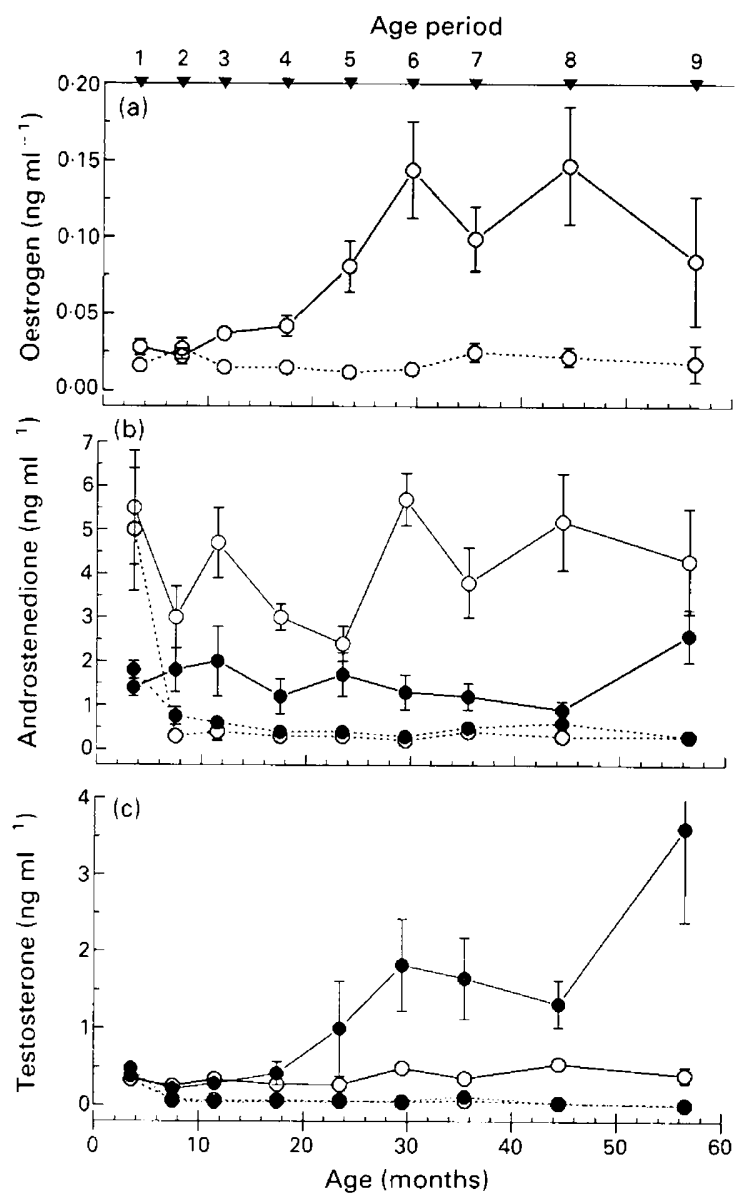

Fig. 2. Mean concentrations ( \pm SEM) of three plasma steroids in a colony of six intact male, two gonadectomized male, eight intact female and four gonadectomized female spotted hyaenas: males $(\bullet)$, females $(\bigcirc)$; values for intact animals $(-)$ and gonadectomized animals $(---)$. Samples were collected between 2 and 60 months of age. Points represent mean values averaged within nine age periods (see top axis). Vertical lines show 1 SEM; where not shown, they are included within the points. (a) Oestrogen (females only), (b) androstenedione; there were significant effects of age $\left(F_{8.28}=5.62, P<0.0001\right)$, sex or gonadal status $\left(F_{3.16}=94.40\right.$, $P<0.0001)$ and the interaction between age and sex or gonadal status $\left(F_{24,128}=2.95\right.$; $P<0.0001$ ); (c) testosterone + dihydrotestosterone. There were significant effects of age $\left(F_{8.128}=6.31, P<0.0001\right)$, sex or gonadal status $\left(F_{3,16}=106.65, P<0.0001\right)$ and the interaction between age and sex or gonadal status $\left(F_{24,128}=4.34, P<0.0001\right)$.

There were no significant differences between intact and ovariectomized females or between intact and castrated males $(P>0 \cdot 10)$ before surgery (age period 1). Removal of the gonads significantly reduced androstenedione concentrations during all postoperative periods for females $(P<0.05)$, and for males during periods 5, 6 and 9 , when intact subjects were compared with gonadectomized subjects within-sex.

'Oestrogen'. Because of sampling limitations, statistical comparisons between groups were limited to intact males versus intact females, and further to age periods 4-9 (Fig. 2a). There were significant effects of age $\left(F_{3,30}=5.87, P<0.01\right)$ and sex or gonadal status $\left(F_{3,10}=30.84\right.$, $P<0.0001)$, but no significant interaction between these variables $\left(F_{9,30}=0 \cdot 76, P>0 \cdot 10\right)$. Intact 
Table 1. Maximum values of androgens in the entire set of data for hyaenas

\begin{tabular}{lccc}
\hline Group & $n$ & $\begin{array}{c}\text { 'Testosterone' } \\
\left(\mathrm{ng} \mathrm{ml}^{-1}\right)\end{array}$ & $\begin{array}{c}\text { Androstenedione } \\
\left(\mathrm{ng} \mathrm{ml}^{-1}\right)\end{array}$ \\
\hline Female & 8 & $1.09(0.93)$ & $11.50(1.45)$ \\
Gonadectomized female & 4 & $0.01(0.0)$ & $0.50(0.10)$ \\
Intact male & 6 & $4.12(0.79)$ & $4.50(0.49)$ \\
Gonadectomized male & 2 & $0.12(0.03)$ & $0.90(0.07)$ \\
\hline
\end{tabular}

Data are means \pm SEM in parentheses.

female hyaenas displayed significantly higher concentrations of plasma oestrogen than intact males at every age period examined (all $t$ test values $>2.80$, all d.f. $\geqslant 9, P<0.05$ ). During age periods $4-9$, only $9 \%$ of individually averaged 'oestrogen' values in intact females were below the threshold of detectability. During the same periods, the proportion of nondetectable average values was much higher in the other three groups: gonadectomized females: $76 \%$, intact males: $55 \%$ and gonadectomized males: $100 \%$.

There were significant effects of age on plasma 'oestrogen' in intact females $\left(F_{8,56}=4 \cdot 43\right.$, $P<0.001)$. Post hoc comparisons indicated that values during age periods 1 and 2 differed significantly $(P<0.05)$ from values during age periods 5-9.

There were no significant differences between female hyaenas in the intact and gonadectomized groups during sampling before surgery (age period 1; Mann-Whitney $U_{7,4}=12, P>0 \cdot 10$ ), or during the immediate postsurgical period (age period 2, $U_{7,4}=10, P>0 \cdot 10$ ). Removal of the ovaries significantly depressed 'oestrogen' concentrations at age periods $4-8(P<0 \cdot 05)$, but small samples precluded an adequate test during the final age period.

Five of the eight intact females in this study underwent multiple pregnancies during the period covered by the present report. Age at conception (calculated as: age at parturition - 110-day gestation) ranged from $26 \cdot 6$ to $41 \cdot 7$ months (mean age at initial conception $=33 \cdot 3 \pm 5 \cdot 5$ months).

\section{Morphology}

Weight. ANOva indicated that there were no significant effects of sex or gonadal status $\left(F_{3.16}=2 \cdot 30, P>0 \cdot 10\right)$, but there was a significant effect of age $\left(F_{8,128}=497.60, P<0.0001\right)$ and a significant interaction between age and condition $\left(F_{24,128}=2.92, P<0.0001 ;\right.$ Fig. 3). Further post hoc comparisons within age periods indicated that the only significant differences in weight were between intact males and females, females being approximately $20 \%$ heavier during age periods 3-9 (Fisher PLSD, all $P<0.05$ ).

Nipple development. Measurements were available for all subjects during age periods 4-6 and a subset of three intact females, two gonadectomized females, three intact males and two gonadectomized males for age periods 2 and 3 (Fig. 4a).

Repeated-measures analyses of variance, using data from age periods $4-6$, indicated a highly significant increment in nipple diameter in intact females $\left(F_{2,14}=40 \cdot 78, P<0.0001\right)$, and post hoc comparisons between age categories were all significant $(P<0.05)$. There were no significant changes during these age periods in intact males $\left(F_{2,10}=1.22, P>0.10\right)$ or gonadectomized females $\left(F_{2,6}=0 \cdot 13, P>0 \cdot 10\right)$. During age period 4 , significant differences were restricted to the comparison between intact females and intact males, but, during periods 5 and 6 , intact females differed significantly $(P<0.05)$ from all three comparison groups, while the remaining groups did not differ significantly from one another (all $P>0 \cdot 10$ ).

Meatus development. Repeated measures ANOVA, using all post-gonadectomy samples indicated that a highly significant increase occurred with age in intact females $\left(F_{4,28}=5 \cdot 34, P<0 \cdot 01\right.$; 


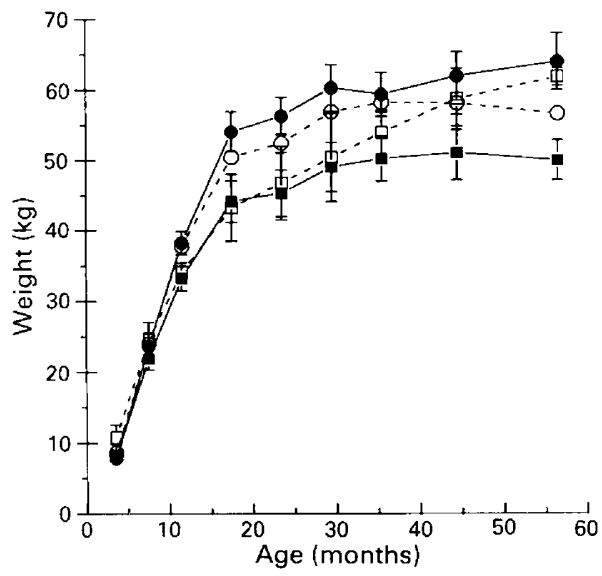

Fig. 3. Body weight in hyaenas as a function of age $\left(F_{8,128}=497.60, P<0.0001\right)$, sex and gonadal status $\left(F_{3,16}=2 \cdot 30, P>0 \cdot 10\right)$. There was a significant interaction between these variables $\left(F_{24,128}=2.92, P<0.0001\right)$. Values for intact females are represented by $(0)$, for gonadectomized females by $(\bigcirc)$, for intact males by $(\boldsymbol{Q})$ and for castrated males by $(\square)$.
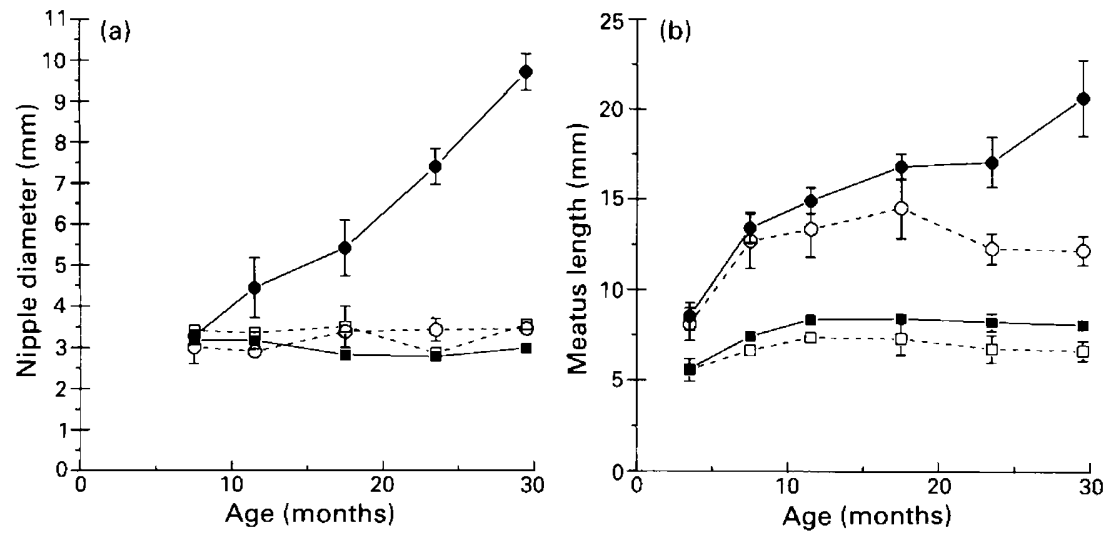

Fig. 4. (a) Nipple diameter and (b) meatus length as a function of age, sex and gonadal status in spotted hyaenas. Values for $(\bullet)$ intact females, $(O)$ gonadectomized females, $(\boldsymbol{D})$ intact males and $(\square)$ castrated males.

Fig. 4b) and a marginally significant increment in intact males $\left(F_{4,20}=2 \cdot 63, P<0.07\right)$, but not in gonadectomized females $\left(F_{4,12}=0 \cdot 74, P>0 \cdot 10\right)$. ANOVA comparing sex and treatment groups, within age periods, were significant during all six age periods studied (all $F_{3,16}>4.34, P<0.05$ ). Before surgery, there were no significant differences in meatus diameter between pregonadectomized females and intact females, although intact males had a significantly smaller meatus than either intact or pregonadectomized females $(P<0.05)$. During age periods $2-4$, after surgery, this pattern persisted, while the difference between gonadectomized females and gonadectomized males also achieved statistical significance $(P<0.05)$, but, during age periods 5 and 6 , a significant difference in meatus diameter emerged between intact and gonadectomized females $(P<0.05)$. During the final age period under consideration (27-32 months), the differences between gonadectomized females and both male groups were no longer statistically significant $(P>0 \cdot 10)$.

Although meatus length increased (Table 2) in all hyaenas when tension on the callipers was increased from 50 to $100 \mathrm{~g}$, changes in intact males, gonadectomized males and gonadectomized 
Table 2. Effects of variation in tension on elasticity of the urogenital meatus in hyaenas

\begin{tabular}{lcccc}
\hline & \multicolumn{4}{c}{ Length of the urogenital meatus $(\mathrm{mm})$} \\
\cline { 2 - 5 } & $\begin{array}{c}\text { Intact } \\
\text { female } \\
(n=8)\end{array}$ & $\begin{array}{c}\text { Gonadectomized } \\
\text { female } \\
(n=4)\end{array}$ & $\begin{array}{c}\text { Intact } \\
\text { male } \\
(n=6)\end{array}$ & $\begin{array}{c}\text { Gonadectomized } \\
\text { male } \\
(n=2)\end{array}$ \\
\hline Tension of $50 \mathrm{~g}$ & $21 \cdot 6(7 \cdot 6)$ & $12 \cdot 7(1 \cdot 5)$ & $7 \cdot 9(0 \cdot 5)$ & $6 \cdot 8(0 \cdot 9)$ \\
Tension of $100 \mathrm{~g}$ & $26 \cdot 2(7 \cdot 1)$ & $13 \cdot 4(1 \cdot 5)$ & $8 \cdot 3(0 \cdot 5)$ & $7 \cdot 1(1 \cdot 1)$ \\
Difference & $4 \cdot 6$ & 0.7 & $0 \cdot 4$ & $0 \cdot 3$ \\
Change $(\%)$ & 21.3 & 6.5 & $5 \cdot 1$ & 4.4 \\
\hline
\end{tabular}

Data are means \pm SEM in parentheses.

females were small $(<6 \%)$. In contrast, the meatus length of intact females increased by $>20 \%$. All increments in meatus length of individual intact females exceeded comparable increments for all other subjects.

\section{Discussion}

\section{Androgens in adult, nonpregnant female hyaenas: are they unusual?}

Because adult females are larger, more aggressive and more dominant than males, there has been a natural interest in the presence of circulating androgens that might account for these sex differences. In terms of absolute concentrations of 'testosterone', reports of plasma values for adult, nonpregnant, female spotted hyaenas have ranged from 0.30 to $1 \cdot 10 \mathrm{ng} \mathrm{ml}^{-1}$ (Racey \& Skinner, 1979; Frank et al., 1985; Lindeque \& Skinner, 1986), encompassing the mean values observed here $\left(0 \cdot 40-0 \cdot 50 \mathrm{ng} \mathrm{ml}^{-1}\right)$. These concentrations are certainly high compared with the radioimmunoassay values reported for many other mammals, e.g. laboratory rats (maximum $0 \cdot 16-0 \cdot 18 \mathrm{ng} \mathrm{ml}^{-1}$ : Dupon \& Kim, 1973), rabbits $\left(0 \cdot 05-0 \cdot 10 \mathrm{ng} \mathrm{ml}^{-1}\right)$, or cows $\left(0.01-0.02 \mathrm{ng} \mathrm{ml}^{-1}\right.$ Wise et al. 1982), as summarized by Feder (1985). However, such values are well within the normal range for a range of female mammals that do not display the exceptional masculinization of the female spotted hyaena; e.g. female brown hyaenas $\left(0.52 \mathrm{ng} \mathrm{ml}^{-1}\right.$ : Racey \& Skinner, 1979), female dogs (0.030-0.70 $\mathrm{ng} \mathrm{ml}^{-1}$ : Olson et al., 1984; Concannon \& Castracane, 1985), Siberian tigers $\left(0 \cdot 200 \cdot 70 \mathrm{ng} \mathrm{ml}^{-1}\right.$ : Seal et al., 1985), rhesus monkeys $\left(0 \cdot 20-0 \cdot 80 \mathrm{ng} \mathrm{ml}^{-1}:\right.$ Feder, 1985) and bonnet macaque monkeys $\left(0.40-1.90 \mathrm{ng} \mathrm{ml}^{-1}\right.$ : Rao \& Kotagi, 1982). Within-species variation in concentrations generally reflects shifts in plasma concentrations of 'testosterone' across the sexual cycle. Our sampling schedule was inadequate to detect potential changes related to ovarian (oestrous) cycles, but such physiological cycles are likely to account for some of the variation in all hormones measured.

There has been some controversy regarding sexual dimorphism in plasma 'testosterone' in adult spotted hyaenas, but the disagreement has been more a matter of interpretation than a conflict between laboratories. In every published report, males have presented higher 'testosterone' concentrations than females, even though this difference did not achieve statistical significance in some studies (Racey \& Skinner, 1979; Lindeque et al., 1986), whereas male female differences did achieve statistical significance in the study by Frank et al. (1986a). It now seems clear, from (a) the new data on average 'testosterone' values presented in this study, (b) analysis of maximum values of 'testosterone' in males and females and (c) examination of data from past and present reports, that average and maximum concentrations of 'testosterone' are higher in adult male than in nonpregnant, adult female hyaenas. However, given the wide variation in 'testosterone' concentrations within and among male hyaenas, the occasional failure to detect statistically significant differences is not surprising. 
There are a number of potential sources of this variability. Frank et al. (1985a) found significant variation in 'testosterone' concentrations of male hyaenas in nature as a function of residence or transience of individuals in a particular clan. Transients are lower ranking than residents and receive aggression from females and resident males. Similar results have recently been reported by Van Jaarsveld \& Skinner (1991). In addition, although functional reproductive maturity may be achieved in males at 2 years of age, plasma values of 'testosterone' increase through subsequent years of maturation. In Lindeque's (1981) sample of adult males, only four of 20 animals were judged to be more than 3 years old. Finally pulsatile secretion of 'testosterone' could account for some of the observed variation in males, as Gombe (1985) has reported in females.

What seems to be unusual about female spotted hyaenas is their consistently high concentration of androstenedione. Average, absolute plasma values of androstenedione in adult, nonpregnant female hyaenas ranged between 3.80 and $5.60 \mathrm{ng} \mathrm{ml}^{-1}$, as a function of age, in the present report. These values are higher than nearly all average concentrations reported for other (nonpregnant) female mammals (Feder, 1985). In terms of ratios, female spotted hyaenas in the present report displayed concentrations of androstenedione that were 2-5 times those in adult males of comparable age. Although adult male mammals of some species (laboratory rats, rabbits and bulls) present higher values of androstenedione than females, female rhesus monkeys and human females have peak values of plasma androstenedione that are typically 1.5-3 times higher than in males, during portions of their reproductive cycle (Feder, 1985). In sum, however, female hyaenas do present an unusually consistent picture of high concentrations of androstenedione, whether compared with other female mammals, or males of their species. Androstenedione, presumably functioning as a prohormone, produces significant activational effects on uterine weight in female rats (Beyer \& Komisaruk, 1971), seminal vesicle growth in male rats (Labrie et al., 1988), mating behaviour in male hamsters (Whalen \& DeBold, 1974) and aggression in male mice (Erpino \& Chappelle, 1971). It seems likely that the high plasma concentrations of androstenedione found in female spotted hyaenas facilitate the appearance of 'masculine' characteristics in these animals.

\section{Sources of circulating androgens}

The present results support the hypothesis of Matthews (1939) and extend the conclusions of Frank et al. (1985b), Lindeque et al. (1986) and Glickman et al. (1987), in suggesting that the ovaries are the primary source of androgens in the female spotted hyaena. Comparisons of ovariectomized and intact subjects indicate that ovarian androgens account for most of the 'testosterone' and 'androstenedione' from the early juvenile period through reproductive maturity (in nonpregnant hyaenas). Extragonadal sources (presumably adrenal) may contribute small amounts to circulating androstenedione, but probably not significantly to 'testosterone' or 'oestrogen'.

Behavioural observations within our colony indicated that, on average, intact females threatened, or attacked, intact males much more frequently than intact males threatened or attacked intact females. However, the reverse situation obtained in ovariectomized subjects. Intact males were more aggressive towards ovariectomized females than such females were towards intact males during spontaneous aggressive encounters (Baker, 1990). Plasma androstenedione, testosterone and oestrogen are all reduced by ovariectomy. Since all three steroids can activate aggression in some species (Erpino \& Chappelle, 1971; Bouissou, 1983; Simon \& Whalen, 1987), determination of which of these steroids normally contributes to the aggressiveness of female hyaenas towards males awaits appropriate hormone replacement experiments.

\section{Gonadal secretions and reproduction in female hyaenas}

Female hyaenas in this study first conceived at the conclusion of their second year, as has been reported in nature (Frank, 1986a). However, the achievement of puberty in female hyaenas is a lengthy process, in which ovarian secretions play a significant role from an early age. Removal of 
the ovaries prevents the normal development of the nipples of the female hyaena beginning at 9-14 months of age. At a later time, associated with a marked rise in oestrogen, the unusual urogenital meatus of the female hyaena lengthens and becomes relatively elastic. This is apparently essential if the female is to be able to receive the male and give birth through this orifice. Such changes in the length and elasticity of the meatus during the late prepubertal period also require ovarian secretions. Thus, ovarian steroids of the spotted hyaena apparently play a dual role: facilitating female reproductive functioning and contributing to female aggressiveness and dominance towards males.

The authors are indebted to D. Sesline and K. Carter for performing the gonadectomies and to M. Weldele and N. Krusko for assistance during many stages of data gathering and analysis. We also thank the Office of the President, the Minister for Tourism and Wildlife and the Department of Wildlife Conservation and Management of the Republic of Kenya for permission to collect and export the infant hyaenas studied in this research.

\section{References}

Baker, M.G. (1990) Effects of ovariectomy on dyadic aggression and submission in a colony of peripubertal spotted hyaenas (Crocuta crocuta). MA thesis, University of California, Berkeley.

Beyer, C. \& Komisaruk, B. (1971) Effects of diverse androgens on estrous behavior, lordosis reflex, and genital tract morphology in the rat. Hormones and Behaviour 2, 217-225.

Bouissou, M.F. (1983) Androgens, aggressive behavior and social relationships in higher mammals. Hormone Research 18, 43-61.

Concannon, P.W. \& Castracane, V.D. (1985) Serum androstenedione and testosterone concentrations during pregnancy and nonpregnant cycles in dogs. Biology of Reproduction 33, 1078-1083.

Dupon, C. \& Kim, M.H. (1973) Peipheral plasma levels of testosterone, androstenedione, and oestradiol during the rat oestrous cycle. Journal of Endocrinology 59, 653-654.

Erpino, M.J. \& Chappelle, T.C. (1971) Interactions between androgens and progesterone in mediation of aggression in the mouse. Hormones and Behaviour 2 , 265-272.

Feder, H.H. (1985) Peripheral plasma levels of gonadal steroids in adult male and adult, nonpregnant female mammals. In Handbook of Behavioral Neurobiology. Vol. 7, pp. 299-370. Eds N. Adler, D. Pfaff \& R. W. Goy. Plenum Press, New York.

Frank, L.G. (1986a) Social organisation of the spotted hyaena (Crocuta crocuta). I. Demography. Animal Behaviour 34, 1500-1509.

Frank, L.G. (1986b) Social organisation of the spotted hyaena Crocuta crocuta. II. Dominance and reproduction. Animal Behaviour 34, 1510-1527.

Frank, L.G., Davidson, J.M. \& Smith, E.R. (1985a) Androgen levels in the spotted hyaena Crocuta crocuta: the influence of social factors. Journal of Zoology, London ( $A$ ) 206, 525-531.

Frank, L.G., Smith, E.R. \& Davidson, J.M. (1985b) Testicular origin of circulating androgen in the spotted hyena Crocuta crocuta. Journal of Zoology, London (A) 206, 613-615.
Frank, L.G., Glickman, S.E. \& Zabel, C.J. (1989) Ontogeny of female dominance in the spotted hyaena: perspectives from nature and captivity. Symposia of Zoological Society of London 61, 127-146.

Frank, L.G., Glickman, S.E. \& Powch, I. (1990) Sexual dimorphism in the spotted hyaena (Crocuta crocuta). Journal of Zoology, London 221, 308-313.

Glickman, S.E., Frank, L.G., Davidson, J.M., Smith, E. \& Siiteri, P.K. (1987) Androstenedione may organize or activate sex-reversed traits in female spotted hyaenas. Proceedings of the National Academy of Science, USA 84, 3444-3447.

Gombe, S. (1985) Short term fluctuations in progesterone, oestradiol and testosterone in pregnant and nonpregnant hyaena (Crocuta crocuta Erxleben). African Journal of Ecology 23, 269-271.

Kruuk, H. (1972) The Spotted Hyena. University of Chicago Press, Chicago.

Labrie, C., Belanger, A. \& Labrie, F. (1988) Androgenic activity of dehydroepiandrosterone and androstenedione in the rat ventral prostate. Endocrinology 123, 1412-1417.

Licht, P., Zucker, I., Hubbard, G. \& Boshes, M. (1982) Circannual rhythms of plasma testosterone and luteinizing hormone levels in golden-mantled ground squirrels (Spermophilus lateralis). Biology of Reproduction 27, 411-418.

Licht, P., Frank, L.G., Pavgi, S., Yalcinkaya, T.M., Siiteri, P.K. \& Glickman, S.E. (1992) Hormonal correlates of 'masculinization' in female spotted hyaenas (Crocuta crocuta). 2. Maternal and fetal steroids. Journal of Reproduction and Fertility 95, 463-474.

Lindeque, M. (1981) Reproduction in the spotted hyaena Crocuta crocuta (Erxleben). MSc thesis, University of Pretoria, South Africa.

Lindeque, M. \& Skinner, J.D. (1982) Fetal androgens and sexual mimicry in spotted hyaenas (Crocuta crocuta). Journal of Reproduction and Fertility 65, 405-410.

Lindeque, M., Skinner, J.D. \& Millar, R.P. (1986) Adrenal and gonadal contribution to circulating androgens in spotted hyaenas (Crocuta crocuta) as 
revealed by LHRH, hCG and ACTH stimulation. Journal of Reproduction and Fertility 78, 211-217.

Matthews, L.H. (1939) Reproduction of the spotted hyaena (Crocuta crocuta Erxleben). Philosophical Transactions of Royal Society London Series B $\mathbf{2 3 0}$, 1-78.

Neaves, W.B., Griffin, J.E. \& Wilson, J.D. (1980) Sexual dimorphism of the phallus of the spotted hyaena (Crocuta crocuta). Journal of Reproduction and Fertility 59, 506-512.

Olson, P.N., Bowen, R.A., Behrendt, M.D., Oldson, J.D. \& Nett, T.M. (1984) Concentrations of testosterone in canine serum during late anestrus, proestrus, estrus and early diestrus. American Journal of Veterinary Research 45, 145-148.

Racey, P.A. \& Skinner, J.D. (1979) Endocrine aspects of sexual mimicry in spotted hyaenas Crocuta crocuta. Journal of Zoology, London 187, 315-326.

Rao, A.J. \& Kotagi, S.G. (1982) Serum testosterone levels during the menstrual cycle and early pregnancy in the bonnet monkey (Macaca radiata). Endocrinologica Japonica 29, 271-275.

Seal, U.S., Plotka, E.D., Smith, J.D., Wright, F.H., Reindl, N.J., Taylor, R.S. \& Seal, M.F. (1985) Immunoreactive luteinizing hormone, estradiol, progesterone, testosterone, and androstenedione levels during the breeding season and anestrus in Siberian tigers. Biology of Reproduction 32, 361-368.

Simon, N.G. \& Whalen, R.E. (1987) Sexual differentiation of androgen sensitive and estrogen sensitive regulatory systems for aggressive behavior. Hormones and Behavior 21, 493-500.

van Jaarsveld, A.S. \& Skinner, J.D. (1991) Plasma androgens in spotted hyaenas (Crocuta crocuta): influence of social and reproductive development. Journal of Reproduction and Fertility 93, 195-201.

Whalen, R.E. \& DeBold, J.F. (1974) Comparative effectiveness of testosterone, androstenedione and dihydrotestosterone in maintaining mating behavior in the castrated male hamster. Endocrinology 95, 1674-1679.

Wingfield, J.C. \& Farner, D.S. (1975) The determination of five steroids in avian plasma by radioimmunoassay and competitive protein-binding. Steroids 26, 311-327.

Wise, T.H., Caton, D., Thatcher, W.W., Lehrer, A.R. \& Fields, M.J. (1982) Androstenedione, dehydroepiandrosterone and testosterone in ovarian vein plasma and androstenedione in peripheral arterial plasma during the bovine oestrous cycle. Journal of Reproduction and Fertility 66, 513-518.

Received 27 March 1991 